\title{
GRAMSCI, CROCE E A HISTÓRIA POLÍTICA DOS INTELECTUAIS
}

\section{Alvaro Bianchi}

https://orcid.org/0000-0001-5201-5923

Universidade Estadual de Campinas (Unicamp), Campinas - SP, Brasil. E-mail: abianchi@g.unicamp.br

DOI: $10.1590 / 349915 / 2019$

Durante todo o lento e penoso processo de pesquisa na prisão, Antonio Gramsci ocupou-se insistentemente em estudar o pensamento de Benedetto Croce (1866-1952) e seu lugar na cultura italiana da época. A pesquisa era multifacetada. É possível perceber, acompanhando o ritmo de composição dos Quaderni del carcere, a emergência e o desenvolvimento de interesses diversos. Ora Croce era um autor-chave para uma investigação sobre a teoria da história, ora aparecia no interior de uma pesquisa filosófica sobre o materialismo e o idealismo, ora era um importante protagonista de uma história dos intelectuais italianos.

Argumenta-se neste artigo que a investigação gramsciana sobre Benedetto Croce, a qual culmina no Quaderno 10, é também parte de uma história política dos intelectuais italianos. Cotejando a lei-

Artigo recebido em: 02/06/2018

Aprovado em: 24/07/2018 tura diacrônica dos Quaderni del carcere com a correspondência que seu autor manteve com Tatiana Schucht e Piero Sraffa, torna-se possível reconstruir o intrincado processo de constituiçáo do objeto e do próprio método de pesquisa que organizou essa investigação. Esse método, que insiste na identidade entre filosofia, história e política, pode fornecer algumas orientaçóes gerais para pesquisas futuras no campo da história intelectual.

\section{Uma história política dos intelectuais italianos}

Imediatamente após o início de seu confinamento na ilha de Ustica, Antonio Gramsci preocupou-se em organizar seus estudos. Na primeira carta que enviou a sua cunhada Tatiana (Tania) Schucht, datada do dia 9 de dezembro de 1926, anunciou quais eram seus planos: "Tenho lido 
sempre, ou quase, revistas ilustradas e jornais esportivos e estou refazendo uma biblioteca. Aqui estabeleci este programa: $1^{\circ}$ estar bem para ficar com a saúde sempre melhor; $2^{\circ}$ estudar as línguas alemã e russa com método e continuidade; $3^{\circ}$ estudar economia e história” (Gramsci, 1973, p. 11). ${ }^{1}$ As requisiçóes de livros que fez em sua correspondência permitem acompanhar essa aventura intelectual. Nessa primeira carta já solicitava a Tania um dicionário de alemão-italiano, um livro de Karl Vossler sobre a história da literatura italiana, um volume de estudos sobre o Rissorgimento e outro de Raffaele Ciasca sobre o programa da unidade nacional (Idem, p. 12).

Dois dias depois o prisioneiro enviou uma carta a seu amigo, o economista Piero Sraffa. ${ }^{2}$ Nela, Gramsci relatou rapidamente que estava em ótimas condições de saúde e lhe encaminhou um pedido:

Dirijo-me a ti para que me faças a cortesia de enviar-me alguns livros. Gostaria de ter um bom tratado de economia e de finanças para estudar; um livro fundamental que poderias escolher a teu juízo. Quando te seja possível envie-me qualquer livro e revista de cultura geral que te pareça interessante para mim. Caríssimo amigo, conheces minhas condiçôes familiares e sabes como é difícil para mim receber livros que não sejam de um amigo pessoal; creia que não teria ousado incomodar-te se não movido pela necessidade de resolver este problema do embrutecimento intelectual que me preocupa especialmente (Idem, p. 15).

A resposta de Sraffa veio rápida, como se pode ver pela carta que Gramsci encaminhou a sua cunhada Tania no dia 19 do mesmo mês, informando que "o amigo Sraffa me escreveu que abriu para mim uma conta corrente ilimitada em uma livraria de Milão" (Idem, p. 23). ${ }^{3}$ Dois dias depois, o prisioneiro escreveu a seu amigo agradecendo-lhe a oferta, informando que já havia feito uma primeira encomenda e contando um pouco de seus planos. $\mathrm{Na}$ ilha, os confinados haviam organizado uma série de cursos elementares de cultura geral. Amadeo Bordiga, que também se encontrava preso no local, era o responsável pela "sessão científica” e Gramsci pela "sessão histórico-literária"; "eis porque encomendei determinados livros", explicou a Sraffa.

O primeiro projeto de pesquisa para os Quaderni del carcere data de 19 de março de 1927 e encontra-se em uma carta que o prisioneiro do fascismo enviou a sua cunhada Tatiana Schucht. ${ }^{4}$ Já nele é possível identificar sua intenção de investigar a função ocupada por Benedetto Croce na vida intelectual da península. Dentre os temas que Gramsci afirmava querer estudar destacava-se:

[...] uma pesquisa sobre a formação do espírito público na Itália do século passado; em outras palavras, uma pesquisa sobre os intelectuais italianos, suas origens, seus reagrupamentos de acordo com as correntes da cultura, seus diversos modos de pensar etc. etc. Argumento sumamente sugestivo que eu, naturalmente, poderei apenas esboçar em grandes linhas, devido à absoluta impossibilidade de ter à disposição a imensa quantidade de materiais que seria necessária. Recordas o rapidíssimo e superficialíssimo escrito meu sobre a Itália meridional e sobre a importância de B. Croce? Bem, gostaria de desenvolver amplamente a tese que havia então esboçado, de um ponto de vista "desinteressado", "für ewig" (Idem, p. 58).

Seu objetivo era retomar aquele ensaio sobre a questão meridional, escrito em 1926, no qual havia delineado uma análise dos intelectuais como uma questão política italiana. Segundo apontou naquele ensaio, a sociedade meridional era um grande bloco agrário que contava em seu vértice com os grandes proprietários rurais e os grandes intelectuais. Caberia a estes últimos as funçôes de centralização e dominação da vida cultural: "Giustino Fortunato e Benedetto Croce representam, por isso, a pedra angular do sistema meridional e, em certo sentido, são as duas maiores figuras da reação italiana" (Gramsci, 1978, p. 150). ${ }^{5}$

Mas Gramsci demorou para dar início à redação dos Quaderni por razóes "técnicas", como costumava dizer, e seu projeto inicial passou por sucessivas revisões. Foi só no começo de 1929 que recebeu autorização para fazer anotaçôes em um caderno e o material necessário para tal. Enquanto isso não deixou 
de estudar febrilmente e de avançar em sua pesquisa. É interessante acompanhar as encomendas que fez à livraria de Milão e as requisições a seus correspondentes, principalmente sua cunhada.

Os livros que encomendou entre dezembro de 1926 e janeiro de 1927 eram, em sua maioria, obras de literatura, história e economia. Os pedidos estão de acordo com os anúncios feitos em dezembro de dedicar-se a estudar "economia e história" e de ter se encarregado da "sessão histórico-literária". Mas em 27 de janeiro de 1927 fez uma encomenda de quatro livros de Benedetto Croce que destoou das antecedentes: Teoria e storia dela storiografia, Storia dela storiografia italiana nel secolo decimonono, Saggio sullo Hegel e Estetica. Aparentemente Gramsci não recebeu alguns desses livros ou não pôde carregá-los consigo quando foi transferido de prisão, pois no dia 14 de novembro de 1927 pediu a sua cunhada que lhe enviasse mais uma vez "Benedetto Croce, Teoria e Storia della Storiografia (Bari, Editori Laterza)" (Gramsci, 1973, p. 145). ${ }^{6}$ Depois, em abril de 1928 solicitou "Benedetto Croce, Storia d'Italia dal 1871 al 1915" (Idem, p. 198); e em dezembro pediu alguns livros que haviam ficado no cárcere de Roma, entre eles "Ben. Croce - La poesia di Dante (Bari, Laterza)", "Ben. Croce - Poesia e non poesia (Bari, Laterza)" e "o n. de setembro da Critica de Benedetto Croce” (Idem, pp. 243-244).

No dia 8 de fevereiro de 1929, Gramsci começou seu trabalho de redação dos Quaderni com uma anotação na qual elencou dezesseis temas sobre os quais pretendia trabalhar. Nesse plano, era apresentada a intenção de organizar uma investigação sobre a "teoria da história e da historiografia". A obra de Croce era um objeto importante dessa investigação, uma área de pesquisa cujo nome remetia ao livro do filósofo italiano, Teoria e storia della storiografia. A insistente requisição desse livro na correspondência precedente é um sintoma de seu interesse. Tatiana provavelmente confundiu-se com os títulos e lhe enviou equivocadamente o livro Storia della storiografia italiana nel secolo XIX, o qual, como visto, Gramsci já havia requisitado à livraria de Milão, embora não seja possível afirmar que o tenha recebido. Sobre os dois livros, comentou em uma carta de dezembro de 1927 :
É verdade que, em certo sentido, os dois trabalhos se integram e seria conveniente, talvez, lê-los conjuntamente, mas do ponto de vista "carcerário" o que recebi [Storia dela storiografia italiana nel secolo XIX] não é o melhor. $\mathrm{O}$ outro [Teoria e storia della storiografia] contém, além de uma síntese de todo o sistema filosófico croceano, também uma verdadeira e própria revisão desse mesmo sistema e pode dar lugar a longas meditações (daí sua específica utilidade “carcerária”) (Idem, p. 157).

A "utilidade carcerária" de Croce estaria, desse modo, fortemente situada de acordo com essa carta de 1927, no âmbito de uma pesquisa sobre a teoria da história e da historiografia. Mas a pesquisa planejada não se restringia apenas a Croce, como as requisiçóes de livros que se seguem podem ajudar comprovar. No dia 11 de março de 1929 escreveu a sua cunhada pedindo que lhe enviasse alguns livros que estavam em sua casa de Roma, dentre eles, mais uma vez, "Benedetto Croce, Storia della storiografia italiana nel sec. XIX", o qual, segundo afirmava "já [...] comprei três vezes e sempre me é roubado" (Idem, p. 259). E, no dia 25 do mesmo mês, solicitou mais três livros do filósofo - "Benedetto Croce Elementi di politica", "B. Croce - Breviario di estetica" e, novamente, "B. Croce - Hegel" - os quais haviam ficado em Roma quando de sua prisão. Esta última requisição era acompanhada de uma síntese daqueles pontos elencados no Primo Quaderno na qual a intenção de investigar a respeito dos intelectuais italianos era reafirmada:

Decidi ocupar-me preponderantemente e tomar notas sobre estes três argumentos: $-1^{\circ} \mathrm{A}$ história italiana no século XIX, com especial atenção à formação e desenvolvimento dos grupos intelectuais; $-2^{\circ}$ A teoria da história e da historiografia; $-3^{\circ} \mathrm{O}$ americanismo e o fordismo. [...] Sobre a teoria da história gostaria de ter um volume francês que saiu recentemente: Boukharine, Théorie du matérialisme historique, Editions Sociales, Rue Valette 3, Paris (5ème) e as Oeuvres philosophiques de Marx, publicadas pelo ed. Alfred Costes, Paris, tomo I: Contribution à la critique de La philosophie 
du droit de Hegel e tomo II: Critique de la critique critique, contro Bruno Bauer e consorti. Os livros mais importantes de Benedetto Croce a propósito já os tenho (Idem, pp. 263-265).

As recomendaçóes de Gramsci mostram o valor que dava às ideias de Croce e o lugar que destinava a elas em suas pesquisas. Mas também revelam sua preocupação em ter ao alcance as fontes necessárias para sua investigação, o caráter minuciosamente planejado de seus estudos e sua concentração no trabalho previamente estipulado. A carta acima citada permite perceber as oscilaçóes no programa de pesquisa gramsciano. Nessa segunda e sintética versão Gramsci restringiu sua pesquisa sobre os intelectuais italianos ao século XIX, o que permite concluir que, neste caso, Benedetto Croce seria uma fonte, mas não um objeto de pesquisa, uma vez que sua atividade mais relevante como organizador da cultura teve início apenas na virada do século, com o lançamento da revista La Critica, em 1903. Essa restrição temporal implicava em um reenquadramento daquela pesquisa que havia tido início em 1926 com a redaçáo de La questione meridionale, ensaio no qual o tema dos intelectuais encontrava seu lugar no século XX.

O plano resumido nessa correspondência permite inferir que Gramsci estaria pensando em excluir Croce de sua investigação sobre os intelectuais italianos e limitar seu interesse na obra do filósofo italiano a seus aspectos historiográficos, ou seja, apenas na medida em que ela fosse uma fonte incontornável para uma pesquisa sobre a "teoria da história e da historiografia”, na qual encontraria lugar sua reflexão sobre a filosofia da práxis. Mas as primeiras notas redigidas para o Primo Quaderno revelam que esse plano de trabalho ainda não se encontrava consolidado e que o ponto de vista de Gramsci a respeito mudava à medida que a pesquisa avançava.

\section{Benedetto Croce como objeto de pesquisa}

Os planos de pesquisa de Gramsci, embora detalhados, eram ainda provisórios e foram sendo redesenhados à medida que a investigação tinha lugar. A pesquisa do ritmo do pensamento grams- ciano indica que em sua investigação o estudo da filosofia encontrava-se integrado com a pesquisa sobre a política e a história. As primeiras referências a Croce nos Quaderni del carcere são apenas ocasionais. No $\$ 10$ do Primo Quaderno, Gramsci referiu-se ao filósofo napolitano, para afirmar que Machiavelli havia tomado a França como exemplo e deduzindo a partir daí a necessidade de um Estado forte para a Itália por meio de uma "comparação elíptica' como diria Croce” (Gramsci, 1977, Q 1, $\$ 10$, p. 19). E no parágrafo seguinte recorreu a Materialismo storico ed economia marxistica para contrapor Croce à concepção de ciência de Luigi Einaudi (Idem, Ibidem).

Nessas fugazes referências fica claro que Croce era uma fonte de pesquisa, uma fonte de inspiração e uma referência incontornável para compreender a cultura italiana. Não tardaria muito, entretanto, para que Croce aparecesse como um objeto de investigação. Mas ao contrário do que se poderia deduzir a partir da análise da correspondência, essa primeira aparição se deu no âmbito de uma ampla pesquisa sobre a formação dos intelectuais italianos e não no interior de uma investigaçáo sobre a teoria da história.

Os primeiros registros do desenvolvimento da pesquisa aparecem em um parágrafo intitulado "Delle università italiane", escrito no terceiro trimestre de 1929. Nele Gramsci se perguntava por que as instituiçôes acadêmicas da península não eram capazes organizar a vida intelectual nacional, ao contrário de suas congêneres em outros países (Idem, Q $1 \$ 15$, p. 12). Para o marxista sardo a relação existente entre professores e alunos nas instituiçóes italianas, nas quais o contato entre aqueles que ensinavam e os estudantes era ocasional e não orgânico, dependia exclusivamente das iniciativas individuais. $\mathrm{O}$ caráter episódico e espontâneo do contato entre professores e alunos nas universidades italianas dificultava o processo de formação de novos grupos intelectuais e tornava essa instituição inadequada e ineficaz perante as exigências de renovação cultural da península. Segundo Gramsci, o mérito de Croce e Gentile esteve, justamente em vivificar essa cultura a partir de uma posição externa ao necrosado ambiente universitário italiano: 
esta estrutura geral da vida universitária não cria, para a universidade, nenhuma hierarquia intelectual permanente entre os professores e a massa dos estudantes; depois da universidade mesmo aqueles poucos laços são afrouxados e nas cidades falta toda estrutura cultural que gire em torno à universidade. Isso constituiu um dos elementos da fortuna da díade Croce-Gentile antes da guerra na constituição de um grande centro de vida intelectual nacional (Idem, Q $1 \$ 15$, p. 13).

Se não era nas universidades que as correntes mais dinâmicas da vida cultural italiana poderiam ser achadas, onde elas, então, estariam? Para Gramsci era nas revistas que as tendências intelectuais mais ativas e inovadoras se encontravam; era por meio delas que a vida cultural e política italiana se expressava e o pensamento se organizava. Revelar as linhas principais de estruturação da vida cultural exigia dar atenção às revistas político-culturais. Gramsci já havia percebido isso e, por essa razão, naquele plano inscrito na primeira página do Primo Quaderno imaginou uma investigação sobre as "Revistas-tipo: teórica, crítico-histórica, de cultura geral (divulgação)".

Torna-se, assim, possível compreender a tenacidade com a qual Gramsci perseguiu os argumentos avançados nas revistas que recebia na prisão, e sua insistência na correspondência em garantir a regularidade das assinaturas ou sua obsessão em receber uma edição específica que não havia sido enviada pela livraria. Dentre as revistas que recebia, La Critica possuía especial importância. Em uma nota presente no Primo Quaderno, Gramsci apontava que a revista de Croce era: "Muito unitária, de modo que havia poucos colaboradores 'principais', ou seja, que escreviam o corpo principal de cada fascículo" (Idem, Q $1 \$ 35$, p. 26). Era um aparelho cultural homogêneo e centralizado, uma força intelectual semelhante a um partido político. Era assim que Gramsci via La Critica. Benedetto Croce era seu secretário-geral. Daí a força que este adquiriu no cenário intelectual italiano.

Essa força era destacada no importantíssimo $\mathbb{S}$ 43, do Primo Quaderno, intitulado "Riviste tipo". O conteúdo do parágrafo indica o caráter histórico e po- lítico de sua reflexão sobre as revistas italianas. Nele Gramsci retomou ideias esboçadas pouco antes da prisão, em sua análise do Mezzogiorno italiano, destacando o lugar dos intelectuais meridionais na vida política nacional. Era a questão dos intelectuais a que se sobressaía: "Benedetto Croce e Giustino Fortunato estão à frente, no início deste século, de um movimento cultural que se contrapóe ao movimento cultural do Norte (futurismo)". Este rapidíssimo enunciado voltaria a aparecer no $\$ 44$ ("Direzione politica di classe prima e dopo l'andata al governo"), uma nota na qual a questão dos intelectuais aparece associada a temas-chaves da reflexão política gramsciana - a hegemonia das classes dirigentes, a revolução passiva e o transformismo. De acordo com Gramsci:

[...] neste século, se realiza um certo bloco "intelectual” que tem à frente B. Croce e Giustino Fortunato e que se ramifica por toda a Itália; em cada pequena revista de jovens que tenham tendências liberal-democráticas e, em geral, se proponham o rejuvenescimento da cultura italiana, em todos os campos da arte, literatura, política (Idem, Q 1, $\$ 44$, p. 48).

Os $\$ \$ 43$ e 44 , escritos entre o final de fevereiro e o início de março de 1930 , retomam ideias esboçadas pouco antes da prisão, em sua análise do Mezzogiorno italiano, destacando o lugar dos intelectuais meridionais na vida política nacional. Eles são um sinal de que o programa de pesquisa gramsciano adquiria contornos políticos mais precisos. Uma parte importante dos argumentos de Gramsci aqui expostos reapareceu em outros cadernos, particularmente no Quaderno 12, no qual retomou, justamente, a questão da formação dos intelectuais italianos, expondo de maneira sintética aquilo que havia enunciado como objetivo de sua pesquisa. Até esse ponto, Benedetto Croce era um capítulo da história dos intelectuais italianos, talvez o mais importante capítulo do século XX. Mas o que interessava primeiramente a Gramsci não era o sistema filosófico croceano e sim como o editor de $\mathrm{La} \mathrm{Cri-}$ tica havia conquistado a hegemonia no ambiente cultural italiano e o alcance desta.

Os meses de fevereiro e março de 1930 foram de intenso trabalho. Gramsci escreveu nesses ses- 
senta dias quase 140 páginas em seu caderno de anotaçóes. No $₫ 132$ do Primo Quaderno, redigido provavelmente em meados de março, suas anotaçóes sobre Benedetto Croce introduziram um novo tema: a atitude política que Croce assumiu perante o marxismo. De acordo com Gramsci as novas correntes do idealismo italiano, particularmente, a gentiliana, faziam coincidir ideologia e filosofia, real e ideal, prática e teoria, degradando o pensamento estritamente filosófico tal qual apresentado na dialética croceana dos distintos, a qual sempre ressaltou a necessidade de separar essas diferentes categorias. Paradoxalmente, essa nova filosofia idealista, apesar do reacionarismo de seus expoentes, conduzia a conclusóes similares às do materialismo histórico e colocava em maus lençóis o idealismo tradicional. Segundo o marxista sardo, Croce teria compreendido esse movimento e resistia com todas as suas forças às pressốes da realidade histórica.

Essa resistência contra as tendências filosóficas contemporâneas teria conduzido Croce a uma cruzada contra o materialismo histórico. Segundo Gramsci, "a preocupação de Croce nasce com a Guerra Mundial e com sua afirmação de que essa é a 'guerra do materialismo histórico'. Sua posição 'au dessus', em um certo sentido é já um índice de tais preocupaçôes e um alarme (na guerra 'ideologia e filosofia' entraram em uma união frenética)”. A conclusão do marxista sardo já desenhava um novo programa de pesquisa no qual o pensamento de Benedetto Croce se tornaria o objeto principal: "Por isso o estudo de seus escritos de [19]19 até hoje é de grande valor" (Idem, Q 1, \$ 132, pp. 119-120).

A passagem acima foi escrita em março de 1930. Poucos meses depois, em maio do mesmo ano, Antonio Gramsci iniciou a redação do Quaderno 4 com uma nova seção, denominada "Appunti di filosofia. Materialismo e idealismo. Prima serie". O título registra a intenção de um estudo sistemático sobre a filosofia, que não se encontrava previsto nos sumários anteriormente redigidos e uma nova ênfase que não havia sido anteriormente indicada em lugar algum sobre as controvérsias entre as concepçôes filosóficas materialista e idealista. O título foi repetido de modo idêntico em uma "Seconda serie", presente no Quaderno 7, e em uma "Terza serie", no Quaderno 8.
Fabio Frosini afirmou que com os "Appunti di filosofia" Gramsci inaugurou um programa de pesquisa teórico sobre o materialismo histórico no qual a centralidade de Croce se justifica pela sua importância. Ao contrário da pesquisa anterior, inscrita no ensaio sobre a questão meridional, dessa vez seriam investigados os pressupostos filosóficos que tornariam possível o surgimento e consolidação dessa figura intelectual (Frosini, 2003, pp. 43-44). Ao acompanhar a evolução da pesquisa gramsciana pode-se perceber que esse programa de pesquisa eminentemente teórico integrava de maneira criativa as dimensões filosófica, histórica e política.

\section{Uma história da cultura moderna}

O $\$ 1$ do Quaderno 4, localizado nos “Appunti di filosofia" sintetiza o método com o qual Gramsci pretendia, inicialmente, organizar sua pesquisa teórica. A preocupação maior de Gramsci estava na dificuldade apresentada por "autores-pensadores" que não expuseram de modo sistemático uma concepçâo de mundo e na qual esta, ao contrário, foi apresentada de modo disperso e fragmentário em grande número de obras de qualidade diversa. Essa situação adversa poderia ser considerada a mais comum quando "se trata de uma personalidade na qual a atividade teórica e a atividade prática são entrelaçadas indissoluvelmente, de um intelecto, portanto, em contínua criação e em perpétuo movimento" (Gramsci, 1977, Q 4, \$ 1, p. 419).

Nesse caso seria fundamental distinguir as obras "que ele [o autor] conduziu até sua conclusão e publicou, daquelas inéditas, porque não concluídas". E no caso de Marx, porque era esse o autor do qual falava, também seria importante distinguir "obras publicadas sobre a responsabilidade direta do autor" daquelas "não publicadas sob a responsabilidade direta do autor". Recomendava ainda cautela no estudo dos materiais preparatórios das obras publicadas, bem como do epistolário (Idem, Q 4, $\$ 1$, pp. 419-420). Toda a ênfase de Gramsci estava posta no desvelamento do "ritmo do pensamento", no Leitmotiv de um autor. O risco maior estaria em confundir o processo de investigação com seu resultado, confundir as fontes mobilizadas durante 
a pesquisa com a concepção de mundo resultante. Segundo o marxista sardo:

É necessário seguir, acima de tudo, o processo de desenvolvimento intelectual do pensador, para reconstruí-lo segundo os elementos que se tornaram estáveis e permanentes, isto é, que foram realmente assumidos pelo autor como pensamento próprio, diferente e superior ao "material" precedentemente estudado e pelo qual ele pode ter tido, em certo momento, simpatia, ou mesmo tê-lo aceito provisoriamente e utilizado para seu trabalho crítico ou de reconstrução histórica ou científica (Idem, Q 4, \$1, p. 419).

Para avançar na pesquisa Gramsci propôs duas tarefas: " $1^{\circ}$ biografia, muito minuciosa com $\left[2^{\circ}\right]$ exposição de todas as obras, até mesmo as mais depreciadas, em ordem cronológica, divididas segundo os vários períodos: de formação intelectual, de maturidade, de posse e aplicação serena do novo modo de pensar". Mas essas tarefas não seriam senão os primeiros passos da pesquisa, elas permitiriam criar as ferramentas necessárias para a investigaçáo, mas não seriam o ponto de chegada da investigação. Segundo Gramsci, essas tarefas seriam "o fundamento do trabalho" de investigação (Idem, Ibidem).

Esse parágrafo esboçava um método para o estudo sistemático da obra de Marx, o qual também poderia ser útil para um programa de pesquisa sobre as ideias de Benedetto Croce. Mas Gramsci, paralelamente a esse programa de pesquisa, apresentou outro programa de investigação sobre a difusão e apropriação do marxismo no mundo contemporâneo. Esse programa está exposto no $\$ 3$ daqueles "Apuntti di filosofia". De acordo com o sardo, o marxismo havia se transformado em um momento da cultura moderna, determinando e fecundando outras correntes intelectuais. Um fenômeno por ele denominado de "dupla revisão" e "dupla combinação" havia tido lugar no final do século XIX e início do século XX. Por um lado "alguns elementos seus, explícita ou implicitamente, tem sido absorvidos por algumas correntes idealistas (Croce, Sorel, Bergson etc., os pragmatistas etc.); por outro os marxistas 'oficiais', preocupados em encontrar uma 'filosofia' que contivesse o mar- xismo, encontraram-na nas derivaçóes modernas do materialismo filosófico vulgar ou ainda em correntes idealistas como o kantismo (Max Adler)". A questão que organizava a investigação de Gramsci era assim, por que "o marxismo teve essa sorte, de aparecer assimilável, em alguns de seus elementos, tanto aos idealistas como aos materialistas vulgares?" Para responder essa pergunta considerava que seria necessário fazer "a história da cultura moderna depois de Marx e Engels" (Idem, Q 4, \$3, pp. 421-422. Grifos meus).

Essa investigação sobre a história da cultura moderna se desenvolveu nos "Appunti di filosofia" do Quaderno 4, em três planos diferentes mas sobrepostos:

1. Uma investigação sobre os problemas atuais do marxismo registrada em notas como " $\$$ [7] Le superstrutture e la scienza", "\$ [8] Machiavelli e Marx"; "§ [10] Marx e Machiavelli"; "§ [11] Problemi fondamentali del marxismo"; "§ [12] Struttura e superstruttura" etc.

2. Uma investigação sobre a revisão materialista do marxismo, cuja expressão maior seria o Saggio popolare de Nicolai Bukharin, a qual encontra sua sede em notas como " $\$[13]$ Note e osservazioni critiche sul Saggio popolare"; "§ [16] La teleologia nel Saggio popolare; "§ [17]. L'immanenza e il Saggio popolare”; "§ [19] Lo 'strumento tecnico' nel Saggio popolare" etc.

3. Uma investigação sobre a revisão idealista do marxismo, cujo expoente era Benedetto Croce, a qual está organizada em notas em sua maioria intituladas "Croce e Marx" (Idem, Q 4, \$\$ 15, 20 e 22 ).

O objetivo dessas pesquisas não era exclusivamente a exposição da teoria-pensamento de um autor, mas, também, o lugar que este poderia ocupar no interior de uma corrente intelectual e política. Gramsci de fato oscilava entre o estudo da obra de um "autor-pensador" e a pesquisa a respeito do desenvolvimento das correntes intelectuais às quais uma obra individual encontrava-se associada. Os dois pontos entre os quais essa oscilação ocorria podem ser considerados complementares. Assim, por exemplo, a investigação sobre o Saggio popolare de Bukharin pareceria ser exclusivamente parte daquela 
pesquisa sobre a teoria da história e da historiografia, muito cedo anunciada pelo marxista sardo. A atenção ao pensamento de Bukharin restringiu-se quase exclusivamente a esse livro, não havia esforço algum em estabelecer uma periodização da obra desse autor ou de reconstruir detalhadamente sua biografia. Ou seja, faltava a essa pesquisa aquilo que o próprio Gramsci considerava ser "o fundamento do trabalho". Mas, à medida que essa obra era conectada a uma corrente, a do marxismo "oficial”, cujo desenvolvimento era apresentado em termos históricos, percebe-se que ela era o objeto de um estudo de caso, parte de uma pesquisa mais abrangente.

O caráter histórico da pesquisa fica mais evidente, entretanto, naquela investigação sobre o pensamento de Benedetto Croce. O objetivo de Gramsci era, nessa pesquisa, revelar o ritmo do pensamento do filósofo italiano e estabelecer uma periodização de suas diferentes fases. No $\$ 15$ desses "Appunti di filosofia”, essa periodização foi estabelecida da seguinte maneira:

$\$ 15$. Croce e Marx. Os acenos que Croce faz a Marx devem ser estudados nos diversos períodos de sua atividade de estudioso e de homem prático. Ele se avizinha de Marx quando era jovem, quando deseja que "as tendências democráticas” entrem em acordo [...] Se afasta nos períodos de democracia até [19]14. Retorna durante a guerra (cf. especialmente o prefácio de 1917 a Materialismo storico ed economia marxistica; e cf. seu juízo, referido por De Ruggiero, de que a guerra era a guerra do materialismo histórico) mas se afasta no primeiro e, particularmente, no segundo pós-guerra, quando uma grande parte de sua atividade crítico-prática tem o objetivo de minar o materialismo histórico porque sente e prevê que ele vai se reafirmar com vigor extremo após a embriaguez das abstraçóes pomposas das filosofias oficiais mas especialmente como consequência das condições práticas e do intervencionismo estatal (Idem, Q 4, \$15, p. 436).

Embora Gramsci encontrasse os diferentes momentos da relação de Croce com o marxismo no interior da obra do filósofo napolitano, procurava estabelecer o nexo entre esses diversos momentos e a política da época. A evolução (ou mesmo involução) do pensamento croceano, o seu ritmo de desenvolvimento, como dizia Gramsci no $\$ 1$ do Quaderno 4, deveria ser encontrado no nexo entre filosofia, história e política.

A perspectiva abrangente dessa pesquisa foi exposta no $\$ 24$ do mesmo caderno. Discutindo a respeito do historicismo na cultura europeia, Gramsci avançou a tese de que o período de restauraçáo, que teve início após a derrota dos jacobinos na França elaborou o historicismo sobre duas linhas: uma que correspondia "à realidade efetiva", recordando uma fórmula de Machiavelli, e outra que se desenvolvia "ideologicamente". Na primeira destas linhas, o historicismo era um programa "civil" que reconhecia o predomínio da grande burguesia. Na segunda delas, esse movimento intelectual corresponderia a uma "filosofia política" que justificava esse predomínio.

Para compreender o historicismo não bastaria estudar uma de suas linhas. Também não seria possível reduzir essa corrente a um movimento exclusivamente filosófico ou historiográfico. Para Gramsci: "É necessário estudar todas estas correntes de pensamento em suas manifestaçóes concretas: $1^{\circ}$ como correntes filosóficas, $2^{\circ}$ como correntes historiográficas, $3^{\circ}$ como correntes políticas" (Idem, Q 4, $\$ 24$, p. 43). O estudo deveria ser integral. Gramsci esboçou nesse parágrafo uma questão metodológica que se tornaria crucial em sua crítica a Croce: a unidade entre filosofia, história e política. Apenas concebendo de maneira unitárias as manifestações filosóficas, históricas e políticas de uma corrente de pensamento seria possível uma história integral da cultura moderna. Mas faltava ainda desenvolver esse método.

\section{Piero Sraffa, o interlocutor oculto}

No dia 3 de julho de 1931, o prisioneiro de Mussolini deu sinais de cansaço e de dúvidas a respeito de sua capacidade de levar a cabo a investigação planejada:

Pode-se dizer que agora eu já não tenho um verdadeiro programa de estudos e trabalho, e 
é claro isso tinha que acontecer. Eu havia me proposto a refletir sobre uma determinada série de questôes, mas deveria ocorrer que, em algum momento, essas reflexóes deveriam passar à fase de documentação e, em seguida, a uma fase de trabalho e elaboração que exige grandes bibliotecas (Gramsci, 1973, p. 459).

No mesmo dia em que redigiu essa carta, Gramsci teve uma crise hemorrágica que prenunciou o agravamento de suas condiçóes de saúde. ${ }^{7}$ Poucos dias depois, Piero Sraffa leu essa carta, endereçada originalmente a Tatiana Schucht, mas sem saber das novas condiçóes de saúde do prisioneiro. Imediatamente o economista entrou em contato com Tatiana, reclamando a respeito das vacilaçōes de seu amigo: "certo, para fazer uma história perfeita dos intelectuais é necessário voltar ao Império romano, e para isso é necessário ter à disposição uma grande biblioteca: mas por que náo fazê-la, no momento, imperfeita? E depois aperfeiçoá-la quando tiver a liberdade e o acesso às bibliotecas" (Sraffa, 1991, p. 23). ${ }^{8}$ Essa carta de Sraffa foi transcrita de modo quase literal por Tatiana e enviada a Gramsci no dia 28 de agosto (Gramsci e Schucht, 1997, pp. 776-778).

Em sua resposta de 7 de setembro à carta de Tatiana e Sraffa, Gramsci procurou tranquilizá-los com relação a sua saúde e comprometeu-se a enviar os resultados preliminares de sua pesquisa sobre os intelectuais: "se tiver vontade e me permitem as autoridades superiores farei um prospecto da matéria que não deverá ter menos de 50 páginas e te enviarei" (Gramsci, 1973, p. 482). A partir de então, Sraffa passou a pedir, sempre por intermédio de Tatiana, que Gramsci escrevesse o prometido resumo do trabalho sobre os intelectuais. ${ }^{9}$ A própria Tatiana cobrou de seu cunhado a redaçáo desse trabalho em uma carta de fevereiro de 1932: "deverias meter-te a escrever o esquema (não menos de 50 páginas!) de tua história dos intelectuais italianos. E se 50 páginas são muitas, comece a mandar uma primeira remessa de 10 páginas" (Gramsci e Schucht, 1997, p. 925). Gramsci respondeu essa cobrança no dia 22 de fevereiro, apontando as dificuldades que encontrava, mas ao mesmo tempo assinalando que pretendia reorganizar seu trabalho em um conjunto de novos cadernos:
Para aquilo que diz respeito às anotaçóes que escrevi sobre os intelectuais italianos não sei exatamente de que lado começar; elas estáo esparsas em uma série de cadernos, misturadas com várias outras notas e deveria primeiramente colocá-las juntas para ordená-las. Este trabalho me custa muito, porque tenho frequentemente as enxaquecas que náo me permitem a concentração necessária, também porque a coisa é, do ponto de vista prático, muito cansativa por causa da maneira e das condiçóes nas quais é preciso trabalhar. Se puder mande-me cadernos, mas náo como aqueles que enviou há algum tempo atrás, que são incômodos e muito grandes; deverias escolher os cadernos de formato normal como aqueles escolares, e com não muitas páginas, no máximo 40-50, de modo que não se transformem, necessariamente, em calhamaços miscelâneos sempre mais confusos. Gostaria de ter estes cadernos pequenos precisamente para reordenar estas notas, dividindo-as por argumento e assim sistematizando-as; isso me fará passar o tempo e me será útil pessoalmente para atingir uma certa ordem intelectual" (Gramsci, 1973, p. 576).

Este reordenamento das notas encontrou seu lugar nos chamados Quaderni speciali, os quais reúnem o ponto mais avançado da elaboração gramsciana $\mathrm{e}$ nos quais a pesquisa sobre Benedetto Croce foi reorganizada. Percebendo uma nova fase no trabalho de pesquisa de seu amigo, Sraffa pediu a Tatiana que the propusesse escrever uma resenha sobre a Storia d'Europa nel secolo decimonono de Benedetto Croce (1999), publicada no início de 1932. Tatiana enviou uma carta a Gramsci no dia 12 de abril, propondo-lhe a resenha: "Receberás dentro de pouco um livro de Croce, La storia d'Europa. Deverias fazer uma resenha porque me interessa muito e tuas observaçóes poderiam ser muito úteis para meu trabalho" (Gramsci e Schucht, 1997, p. 972). Sraffa, que não sabia dessa carta, insistiu com Tatiana no dia 21 de abril: "Quando escrever para Nino você deveria insistir para que encaminhe, por carta, uma espécie de resenha do livro de Croce" (Sraffa, 1991, p. 58).

Gramsci pôs-se a trabalhar imediatamente, antes mesmo de receber o livro. ${ }^{10}$ Em uma carta do 
dia 18 de abril, enviada a Tatiana, procurou fixar alguns pontos que considerava úteis "para fazer a pesquisa”. A primeira questão a ser respondida, segundo o sardo, era esta: "quais são os interesses culturais hoje dominantes na atividade literária e filosófica de Croce, se esses são de caráter imediato e de envergadura mais geral e referentes a exigências mais profundas que não aquelas nascidas das paixões do momento" (Gramsci, 1973, p. 607).

A resposta a essa pergunta não era ambígua. Segundo Gramsci a atividade literária e filosófica de Croce havia adquirido um novo sentido com a Guerra Mundial. ${ }^{11}$ A partir desse evento trágico o empreendimento intelectual do filósofo napolitano estaria voltado a encontrar as possibilidades de soluções mediadas e de compromisso entre as várias forças históricas em conflito: "Croce vê sempre no momento da paz o momento da guerra e no momento da guerra o da paz e volta sua atividade para impedir que seja destruída toda possibilidade de mediaçáo e compromisso entre os dois momentos" (Idem, p. 608).

Se a primeira questão dizia respeito ao programa político-intelectual de Croce, a segunda dizia respeito ao lugar por ele ocupado "no campo da cultura mundial". O filosofo napolitano deveria ser considerado um líder do revisionismo, uma posição da qual ele próprio era consciente. Sua influência sobre Georges Sorel e Eduard Bernstein teria sido decisiva para o desenvolvimento de uma corrente revisionista europeia. Essa atividade revisionista teria adquirido uma nova dimensão com "a elaboração de sua teoria da história como história ético-política (e isto é, quase toda sua atividade de pensador nos últimos 20 anos)" (Idem, p. 609).

Gramsci acrescentaria uma questão adicional para a investigação em uma carta de 25 de abril. Nesta missiva considerava necessário refletir sobre a grande difusão da obra de Croce. Uma das razóes principais dessa fortuna era o estilo com o qual ele escrevia, o qual the permitia: "fazer circular de modo não pedante sua concepção de mundo em uma série de breves escritos nos quais sua filosofia se apresenta imediatamente e é absorvida como bom senso ou senso comum" (Idem, p. 613). A própria questão da força hegemônica do pensamento croceano era posta por essa questáo de pesquisa, a qual propunha in- quirir a respeito de sua capacidade de difusão e da direção que exercia sobre grupos mais amplos de intelectuais, localizados nas universidades, nas escolas, nos jornais e nas revistas.

Embora trabalhasse intensamente em sua pesquisa sobre Benedetto Croce, ainda tinha dúvidas se conseguiria terminar o prometido ensaio sobre os intelectuais italianos. ${ }^{12} \mathrm{~A}$ sequência de sua investigação sobre Croce está registrada na carta a Tatiana datada de 2 de maio, na qual retomou a questão referente à intenção revisionista do empreendimento filosófico e historiográfico croceano, destacando desta vez que "esse trabalho de pensamento nestes últimos vinte anos está guiado pela finalidade de completar a revisão com vistas a torná-la uma liquidação" do marxismo (Idem, p. 615).

Essa nova ênfase foi percebida por Sraffa, que por meio de Tatiana acompanhava a reflexão de Gramsci a respeito de Croce e procurava fornecer-lhe novas informaçóes e ideias para a pesquisa. Em uma carta a Tatiana de 30 de abril, o economista narrou ter encontrado um amigo de Croce, o qual teria lhe dito que o filósofo abruzês estava convencido de que o "materialismo histórico não tem nenhum valor, nem como cânone prático de interpretação" (Sraffa, 1991, p. 62). ${ }^{13}$ Gramsci reagiu no dia 9 de maio a essa provocação intelectual expondo sua interpretação sobre a história ético-política de Croce, a qual suprimia na análise "o momento da força e da luta” (Gramsci, 1973, p. 619). Essa supressão teria uma motivação fundamentalmente prática e um maquiavelismo que levaria Croce a mudar de lado de acordo com as circunstâncias:

Croce vive a tese e a antítese do processo histórico e insiste em uma ou outra por "razóes práticas" porque no presente vê o futuro e dele se preocupa tanto quanto do presente. A cada um a sua parte: aos sacerdotes aquela de salvaguardar o amanhã. No fundo há uma bela dose de cinismo moral nesta concepção "éticopolítica”; é a forma atual do maquiavelismo (Idem, p. 621).

Sem saber da resposta de Gramsci nessa carta, Sraffa voltou a tocar no tema em uma carta de 16 de maio de 1932 na qual pediu que Gramsci desen- 
volvesse melhor sua visão a respeito da relação de Croce com o marxismo:

Poderias pedir a Nino que trace com precisão o desenvolvimento da posição de Croce com relação à concepção materialista da história e que explique um pouco as razóes da mais recente fase, de absoluta e completa oposição, como aparece em sua Storia d'Italia e Storia d'Europa. Como se vincula esta última mudança com a mudança geral de Croce depois de sua ruptura com Gentile? Seria exato dizer que ele é constrangido a refugiar-se na "religião da liberdade" e fantasias similares para esconder o fato de que ele e seus amigos perderam o terreno sob seus pés, sem esperança de reencontrá-lo? (Sraffa, 1991, p. 66).

Tatiana transcreveu para seu cunhado de modo literal essas perguntas em uma carta de 30 de maio de 1932. Gramsci respondeu no dia 6 de junho, demonstrando um pouco de irritação com as perguntas, afirmando não entender a importância delas e dizendo que já as havia respondido nas cartas precedentes. Ainda assim procurou escrever sobre aquilo que não havia ainda refletido na correspondência anterior. A questáo de fundo continuava a ser o lugar de Croce na cultura italiana. Gramsci questionou a ideia de que Croce tivesse perdido "o terreno sob seus pés e se encontrava isolado": "você talvez exagere a posição de Croce no momento presente, considerando-o mais isolado do que está" (Gramsci, 1973, p. 632).

Como demonstrou Frosini, essa carta rompe um padrão de escrita previamente estabelecido e rigorosamente seguido pelo prisioneiro. Para evitar a censura, Gramsci evitava referir-se a temas diretamente políticos em sua correspondência, a qual era sempre submetida ao olhar atento das autoridades carcerárias, podendo acarretar o confisco e sançôes disciplinares. Outros eram os cuidados tomados com a redação dos Quaderni, os quais não eram controlados sistematicamente, razão pela qual o prisioneiro julgava ter um pouco mais de liberdade para sua escrita (Frosini, 2015, pp. 48-51).

Gramsci argumentava nessa missiva que Croce, longe de encontrar-se sozinho, havia penetrado na própria cultura do fascismo italiano e suas ideias eram divulgadas em revistas como Politica, dirigida pelos fascistas Francesco Coppola e Alfredo Rocco. Para certos dirigentes fascistas as ideias do filósofo napolitano eram de grande utilidade para a educaçáo dos novos grupos dirigentes que haviam surgido depois da guerra. O processo de conformação dos grupos dirigentes italianos desde 1815 tinha ocorrido por meio da constante absorção das forças políticas de oposição nascidas no interior dos movimentos de massa. Esse processo, conhecido como transformismo e já tratado por Gramsci no Primo Quaderno, havia assumido uma importante conformação depois da guerra, quando o esgotamento das velhas classes dominantes tornara-se evidente $\mathrm{e}$ novos grupos sociais pressionavam para ingressar na vida política. As ideais de Croce revelaram-se funcionais para esse processo, elas constituíam a própria filosofia e historiografia do transformismo político. Segundo Gramsci:

Colocada em uma perspectiva histórica, da história italiana, naturalmente, a operosidade de Croce aparece como a máquina mais potente para "conformar" as forças novas aos interesses vitais (não apenas imediatos, mas também futuros) que o grupo dominante hoje possua e que eu creio deseje justamente, apesar de toda aparência superficial (Gramsci, 1973, p. 633).

Era, pois, sobre a relação entre Croce e o fascismo e o processo de conformação de uma nova hegemonia burguesa que Gramsci julgava urgente escrever e por essa razão rompeu a regra de autocensura previamente estabelecida, abandonando as cautelas usuais. ${ }^{14}$ É provável que o prisioneiro tivesse percebido sinais de recrudescimento da censura e, por essa razão, julgado necessário um último e arrojado movimento. De fato, Sraffa escreveu ainda uma carta no dia 21 de junho de 1932 solicitando alguns esclarecimentos pontuais a respeito do argumento de Gramsci, os quais foram transmitidos por Tatiana em uma correspondência de 5 de julho (Gramsci e Schucht, 1997, pp. 1041-1042; Sraffa, 1991, pp. 72-73). Esse intercâmbio intelectual por intermédio de Tatiana foi, entretanto, suspenso devido às limitaçóes impostas pelas autoridades 
prisionais, as quais restringiram ainda mais a correspondência dos presos, e pelo simultâneo agravamento das condiçôes de saúde de Gramsci. ${ }^{15}$

\section{Filosofia, história e política}

Essa troca de correspondência com a sugestão de uma resenha sobre a obra de Benedetto Croce coincidiu perfeitamente com a redação de um importante conjunto de notas sobre Croce nos "Appunti di filosofia. Materialismo e idealismo. Terza serie", localizados no Quaderno 8 (\$\$ 225, 227, 233, 236 e 240) e com o início da redação do Quaderno 10, dedicado à filosofia de Benedetto Croce. Francioni apresenta a hipótese de que Gramsci tenha usado as notas do Quaderno 8 como um rascunho para as cartas que escreveu atendendo à solicitação de uma resenha e que, imediatamente depois, tenha desenvolvido as ideias contidas na correspondência no conjunto de notas que abrem a segunda seção do Quaderno 10 (Francioni, 1984, pp. 103-104). ${ }^{16}$

As notas presentes no Quaderno 10/II reúnem a reflexão mais elaborada de Gramsci a respeito de Croce. Nesse quaderno, Antonio Gramsci iniciou uma série de notas sobre o filósofo napolitano estabelecendo alguns critérios gerais metodológicos para sua crítica. Esses critérios são muito úteis não apenas para esclarecer os propósitos da investigação, mas também para evidenciar o método de pesquisa gramsciano. Esse método foi resumido em quatro pontos:

1. Não procurar em Croce um "problema filosófico geral”, mas ver em sua filosofia aquele problema ou aquela série de problemas que mais lhe interessam no momento dado, que são, isto é, mais aderentes à vida atual e são como seu reflexo $[\ldots]$.

2. É necessário estudar atentamente os escritos "menores" de Croce, isto é, além de suas obras sistemáticas e orgânicas as coletâneas de artigos, de anotaçóes, de pequenas memórias que têm uma ligação maior e mais evidente com a vida, com o movimento histórico concreto.

3. É necessário estabelecer uma "biografia filosófica" de Croce, isto é, identificar as diversas ex- pressóes assumidas pelo pensamento de Croce, a diversa colocação e resolução de certos problemas, os novos problemas que surgem de seu trabalho e se impóem a sua atenção [...].

4. Críticos de Croce: positivistas, neo-escolásticos, idealistas atualistas. Objeções desses críticos (Gramsci, 1977, Q 10/II, p. 1239). ${ }^{17}$

Resulta interessante comparar essa nota com aquele $\$ 1$ do Quaderno 4 ao qual já foi feita referência. Ao contrário da nota precedente, Gramsci se mostrava, nesta última, menos interessado nos aspectos “tornados estáveis e permanentes" e mais interessado no próprio ritmo do pensamento. Ou seja, reencontrar esse ritmo deixava de ser um meio para revelar um "problema filosófico geral" e passava a ser a razão da própria pesquisa. Pois era nesse ritmo que a filosofia se conectava com a vida prática. Era por meio dele que a política e a história impregnavam o pensamento de um autor "como seu reflexo".

Por essa razão os escritos filosóficos menores, os mesmos que haviam sido desvalorizados naquela nota do Q 4, ganhavam uma nova importância no Q 10. As "coletâneas de artigos, de anotaçōes, de pequenas memórias" registrariam o movimento do pensamento de um autor e a maneira pela qual este enfrentaria filosoficamente os problemas políticos do cotidiano e "o movimento histórico concreto". Uma revalorização desses escritos menores permitiria construir a "biografia filosófica" de um autor, particularmente de Croce, mapeando as diversas soluçóes dadas a certos problemas e os novos problemas que teriam sido colocados pelo desenvolvimento de seu trabalho de investigação.

Por último, Gramsci chamou a atenção de que não era possível reconstruir essa biografia filosófica e nem mesmo o ritmo do pensamento de um autor sem estudar, ao mesmo tempo, as críticas que ele recebeu em seu tempo e as respostas que formulou a essas críticas. Para compreender o movimento do pensamento seria necessário restabelecer o diálogo crítico de um autor com seus contemporâneos. O resultado final da investigação não poderia deixar de ser, desse modo, um amplo afresco do ambiente cultural e político de sua época.

O pressuposto teórico a esse método pode ser encontrado poucas páginas adiante no $\$ 2$ do 
Quaderno 10/II no qual era anunciada a identidade entre filosofia, história e política. Trata-se de uma nota que não se encontrava precedentemente nos cadernos miscelâneos e que foi redigida especialmente para esse estudo sobre Benedetto Croce presente no primeiro dos cadernos especiais. Gramsci afirmou nesse parágrafo que a identidade entre história e filosofia posta pelo filósofo napolitano era "imanente no materialismo histórico" e se perguntava se Croce não teria encontrado essa identidade na obra de Antonio Labriola.

Embora esse postulado croceano fosse dos mais ricos para o desenvolvimento da filosofia da práxis, ele se encontrava incompleto. Segundo Gramsci, " 10 essa [a identidade entre filosofia e história] é mutilada se não atinge também a identidade de história e de política [...] e, 20 também a identidade de política e de filosofia" (Idem, Q 10/II, \$12, p. 1241). A afirmação da identidade entre filosofia, história e política permitia redesenhar cada um desses conceitos, abolindo as fronteiras estabelecidas pelo sistema croceano.

Os impasses desse sistema ficavam claros na Storia d'Europa. Separando por meio da dialética dos distintos a realidade em movimento do conceito de realidade, seu autor teria produzido "uma história formal, uma história dos conceitos e, em última análise, uma história dos intelectuais; aliás, uma história autobiográfica do pensamento de Croce, uma história de presunçosos" (Idem, Q 10/ II, $₫ 11$, p. 1241). A historiografia croceana investigava o processo por meio do qual ideias geravam autonomamente ideias. Esse viés fortemente idealista poderia ser, entretanto, superado concebendo a historiografia como um ato político:

Se o político é um historiador (não apenas no sentido de que faz a história, mas também no de que, atuando no presente interpreta o passado) o historiador é um político; e nesse sentido (que de resto aparece também em Croce), a história é sempre história contemporânea, isto é, política (Idem, Q 10/II, $\$ 12$, p. 1242).

Esse postulado permite compreender as observaçóes metodológicas presentes no início do Quaderno 10/II. Gramsci estava interessado em estudar o pensamento de um autor de grande importância no contexto cultural de sua época e considerava que esse havia se ocupado também dos problemas políticos contemporâneos, ou seja, que sua filosofia expressava esses problemas. Mas a busca desses problemas políticos e a reconstrução do contexto histórico no qual eles tiveram lugar deveria nascer da própria obra que se estudava e na relação desta com os acontecimentos de seu presente e com o conjunto de obras que conformam seu presente intelectual.

Gramsci não estava interessado em revelar as motivações contingentes da reflexão croceana, nem considerava essa um mero epifenômeno ou uma resposta mecânica dos conflitos próprios do mundo contemporâneo. A questão que procurava investigar dizia respeito à participação de Croce nesses conflitos, por meio de sua filosofia e sua historiografia, ou seja, procurava revelar o caráter político destas. Por isso a importância de ir além das grandes obras e de reconstruir essa participação nos debates na imprensa, na correspondência privada, nas resenhas e escritos de ocasião, explorando uma literatura "menor" em seu alcance e em suas intençóes originais, mas ainda assim extremamente significativa para uma história política dos intelectuais.

A identidade entre filosofia, história e política deve ser compreendida como uma "equação", de acordo com Gramsci, ${ }^{18}$ ou seja, no sentido de que os diferentes momentos expressam o mesmo conteúdo sob diferentes formas, assim como ocorre em uma equação matemática (a respeito, Frosini, 2010, p. 30). Não se trata, pois, de dissolver a história ou mesmo a política na filosofia, como ocorre frequentemente na obra de Benedetto Croce, mas de destacar o conteúdo político que a história e a filosofia podem assumir.

Concebida como uma equação, essa identidade entre a filosofia, a história e a política permitiria compreender melhor o lugar do filósofo e do historiador como políticos, ou seja, em que medida a filosofia e a historiografia seriam também atos políticos, intervençôes intelectuais em contextos determinados. Ora, para uma perspectiva historicista que destaque a identidade entre filosofia, história e política não seria nem necessário nem desejável entender o corpo de um pensamento, puramente ou até principalmente, dentro da intenção consciente do autor. Os efeitos práticos de seu pensamento 
seriam tão importantes para o intérprete quanto o que ele realmente desejaria transmitir: "uma corrente filosófica deve ser criticada e avaliada não por aquilo que pretende ser, mas por aquilo que realmente é e se manifesta nas obras históricas concretas” (Gramsci, 1977, Q 10/I, \$12, p. 1235).

Assim, é importante perceber que um autor pretende intervir em um contexto específico com sua obra ou suas ideias, mas que também o intérprete contemporâneo, o historiador, está fazendo política com sua interpretação do passado. Com base nessa noção é possível perceber que o contexto no qual o pensamento político adquire significado não é exclusivamente aquele no qual ele foi produzido, mas é, também, aquele no qual ele foi apropriado. Do mesmo modo, esses significados não são atribuídos somente pelos autores, mas também pelos próprios contextos históricos nos quais eles são produzidos e/ou reelaborados, nos conflitos sociais e políticos que têm aí lugar.

\section{Conclusão}

A história intelectual perdeu sempre que a pesquisa se reduziu a uma mera ilustração do método de investigação. Por essa razão, é preciso ter em mente que "toda pesquisa científica cria um método adequado, uma lógica própria" (Idem, Q 6, $\mathbb{S}$ 180, p. 826). Foi com essa perspectiva que Gramsci pesquisou a história dos intelectuais italianos e a posição que Benedetto Croce ocupou nela. O método que esboçou para essa investigação pode ser encontrado nos pequenos fragmentos metodológicos nos quais procurou explicitá-lo, mas principalmente na própria pesquisa. É um método que se revela à medida que a investigação avança.

Os Quaderni del carcere de Antonio Gramsci não são uma obra terminada. Eles são inacabados, fragmentários e assistemáticos. Registros de uma pesquisa em ato, são o laboratório no qual as ideias de seu autor foram destiladas. Por essa razão não é possível distinguir em seu interior entre o método de investigação e o método de exposição. Ambos encontram-se amalgamados a tal ponto que reconstruir o argumento do autor exige, também, a reconstrução de seu método de investigação.
A reconstrução do método particular que Gramsci desenvolveu para sua investigação sobre a história dos intelectuais permite compreender melhor seu projeto e, ao mesmo tempo, pode fornecer pistas interessantes para pesquisadores interessados nesse campo de estudos. Reconstruí-lo foi o objetivo do presente artigo. Partindo do pressuposto da identidade entre história, filosofia e política, Gramsci considerava todo pensamento historiográfico ou filosófico como um movimento na luta política dos partidos; procurava apreender esse movimento político no interior do próprio processo de produção das ideias e do registro desse processo nos textos; e enfatizava que para isso era preciso ir além do estudo das "grandes obras" de um autor, estudando os escritos menores e de ocasião, os artigos publicados na imprensa, as entrevistas, as anotaçóes autobiográficas e a correspondência de um autor, textos nos quais seria possível encontrar a solução para as aporias presentes nos tratados e obras sistemáticas.

Esse método fornece algumas soluções interessantes para o debate atual entre as abordagens históricas e filosóficas da história das ideias. A fusão de tais abordagens em um método comum, o qual considera filosofia, história e política diferentes formas de um mesmo conteúdo permite superar certos formalismos presentes na discussão contemporânea que se desenvolveu a partir da publicação da conhecida contribuição de Quentin Skinner (1969). Gramsci denominou esse método de "filologia da história e da política” (Idem, Q 16, $\$ 13$, p. 1845), uma abordagem atenta à "individualidade" dos fatos particulares.

\section{Notas}

1 As traduções ao longo do texto, salvo quando informadas, são do autor.

2 De acordo com Giuseppe Vacca, provavelmente a primeira carta que Sraffa enviou a seu amigo em Ustica no dia 13 de dezembro foi combinada com a direçáo do partido. A partir desse momento o economista de Cambridge passou a ser um elo de ligação entre o partido e Gramsci (Vacca, 2012, p. 105). Mas é importante destacar que a iniciativa coube a Gramsci, que lhe escreveu no dia 11 de dezembro. Foi o prisioneiro quem escolheu seu interlocutor. Em uma literatura 
recente marcada pelo sensacionalismo, Sraffa é apresentado como um agente do Partido Comunista e da Internacional Comunista, uma "toupeira soviética [Soviet mole]" como chegou a afirmar Luciano Canfora (2012, p. 97). A acusaçâo não era nova, muito antes Maria-Antonietta Macchiocchi, em um livro hoje de pouca relevância, já havia se referido a Sraffa como "o homem que gozava da confiança de Togliatti, do partido, da família de Gramsci", colocando sob suspeita sua integridade (Macciocchi, 1977, p. 274). Recentemente, Giancarlo de Vivo demonstrou de maneira muito convincente que Sraffa náo agia de modo subordinado, desconfiava da direçáo do partido e chegou a ocultar deste certas cartas de Gramsci (Vivo, 2017, pp. 38-52).

3 Ainda de acordo com Vacca, este generoso gesto também contou com o apoio do partido (Vacca, 2012, p. 105).

4 Sobre os diferentes planos da pesquisa registrada nos Quaderni, ver Baratta (2003) e Frosini (2003).

5 O ensaio, escrito em 1926 foi publicado apenas em 1930 com o título "Alcuni temi dela questione meridionale" na revista Lo Stato Operaio, mantida pelo PCd'I em Paris.

6 No dia 20 de janeiro de 1927 Gramsci foi transferido da prisão em Ustica para o cárcere judiciário de Milano, onde seria processado pelo Tribunal Especial. A viagem durou 19 dias e se tornou extenuante para o priosioneiro. Ver relato em (D’Orsi, 2017, pp. 224225); o próprio Gramsci descreve as difíceis condiçōes nas quais a viagem ocorreu em uma carta de 12 de fevereiro (Gramsci, 1973, pp. 45-48).

7 A crise foi narrada por Gramsci em sua carta do dia 17 de agosto de 1931 (Gramsci, 1973, pp. 464-467).

8 A partir de 1929 a correspondência Gramsci e Sraffa ocorre por intermédio de Tatiana Schucht, a qual repassava as cartas do prisioneiro e copiava as missivas do economista como se fossem suas. As cartas de Sraffa foram coligidas por Gerratana em um livro de enorme utilidade para os pesquisadores (Sraffa, 1991).

9 Conforme as cartas de 3 de outubro de 1931 (Sraffa, 1991, p. 36) e 27 de dezembro de 1931 (Sraffa, 1991, p. 43).

10 As autoridades prisionais demoraram para entregar-lhe o livro Storia d'Europa. Gramsci, entretanto, já havia lido os três primeiros capítulos deste, os quais consistiam em uma conferência que Benedetto Croce havia pronunciado em 1931 na Accademia di Scienze Morali e Politiche della Società Reale di Napoli.

11 Como visto, já no Primo Quaderno Gramsci havia anotado que o pensamento de Benedetto Croce havia sofrido uma inflexão com a guerra.
12 Em 2 de maio de 1932 escreveu a Tatiana: "Não sei se mandarei o esquema que tinha prometido sobre os 'intelectuais italianos'. O ponto de vista a partir do qual observo a questấo muda às vezes e talvez seja ainda cedo para resumi-lo e sintetizá-lo" (Gramsci, 1973, p. 615).

13 Tatiana transmitiu a Gramsci o conteúdo dessa conversa em uma carta de 5 de maio de 1932 (Gramsci e Schucht, 1997, p. 996).

14 O caráter propriamente político dessa correspondência é analisado minuciosamente por Frosini (2015).

15 Gramsci adverte Tatiana a respeito do conteúdo das cartas em uma correspondência do dia 12 de julho de 1932: "Acho útil, por isso, insistir mais uma vez advertindo-te: [...] Que nas tuas cartas seria bom que você não me falasse de nada além das coisas familiares, da maneira mais clara e perspícua possivel" (Gramsci, 1973, p. 646; ver a respeito Vacca, 2012, pp. 289-290). E no dia 18 de julho, informa a Tatiana a respeito de suas condições de saúde, as quais afetavam seu trabalho intelectual: "há cerca de um mês não estou muito bem. [...] De todo modo me tornei incapaz de qualquer forma de concentraçáo intelectual, mesmo aquela mínima necessária para escrever uma carta" (Gramsci, 1973, p. 648).

16 As cartas que Gramsci escreveu sobre o tema são dos dias 18 e 25 de abril, 2 e 9 de maio. Elas correspondem aos $\$ \$ 225,227,233$ e 236 escritos quase simultaneamente no Quaderno 8 e depois reescritos na Seção Punti di riferimento per um saggio su B. Croce, que constituem as últimas dez páginas do Quaderno 10. Sobre a composiçáo dos cadernos 8 e 10 , ver também Francioni (2009) e Frosini (2009).

17 Embora estas notas ocupem a segunda parte do Quaderno 10 elas foram redigidas previamente à primeira parte, conforme foi estabelecido por Gianni Francioni (1984).

18 "Desta forma, chega-se também à igualdade ou equaçâo entre "filosofia e política", entre pensamento e ação, isto é, a uma filosofia da práxis" (Gramsci, 1977, Q7, \$35, p. 886).

\section{BIBLIOGRAFIA}

BARATTA, Giorgio. (2003), Le rose e i quaderni: il pensiero dialogico do Antonio Gramsci. Roma, Carocci.

CANFORA, Luciano. (2012), Spie, URSS, antifascismo: Gramsci, 1926-1937. Roma, Salerno.

D'ORSI, Angelo. (2017), Gramsci: una nuova biografia. Milano, Feltrinelli. 
FRANCIONI, Gianni. (1984), L'officina gramsciana: ipotesi sulla struttura dei Quaderni del carcere. Napoli, Bibliopolis.

FRANCIONI, Gianni. (2009), "Nota introdutiva al Quaderno 8 (1930-1932)”, in A. Gramsci, Quaderni del carcere: edizione anastatica dei manoscritti, Roma/Cagliari, Istituto della Enciclopedia Italiana/L'Unione Sarda.

FROSINI, Fabio. (2003), Gramsci e la filosofia: saggio sui Quaderni del cárcere. Roma, Carocci.

FROSINI, Fabio. (2009), "Nota introdutiva al Quaderno 10 (1932)", in A. Gramsci, Quaderni del carcere: edizione anastatica dei manoscri$t t i$, Roma/Cagliari, Istituto della Enciclopedia Italiana/L'Unione Sarda.

FROSINI, Fabio. (2010), La religione dell'uomo moderno: politica e verità nei Quaderni del carcere di Antonio Gramsci. Roma, Carocci.

FROSINI, Fabio. (2015), "Sulle 'spie' dei Quaderni del carcere”. International Gramsci Journal, 1 (4): 43-65.

GRAMSCI, Antonio. (1973), Lettere dal carcere: a cura di Segio Caprioglio e Elsa Fubini. Torino, Einaudi.

GRAMSCI, Antonio. (1977). Quaderni del carcere: edizione a cura di Valentino Gerratana. Torino, Enaudi.

GRAMSCI, Antonio. (1978), La costruzione del Partito Comunista, 1923-1926. Torino, Einaudi.

GRAMSCI, Antonio \& SCHUCHT, Tatiana. (1997), Lettere (1926-1935): a cura di Aldo Natoli e Chiara Daniele. Torino, Einaudi.

MACCIOCCHI, Maria-Antonietta. (1977), A favor de Gramsci. 2. ed. Rio de Janeiro, Paz e Terra.

SKINNER, Quentin. (1969), "Meaning and understanding in the history of ideas". History and Theory, 8 (1): 3-53.

SRAFFA, Piero. (1991), Lettere a Tania per Gramsci: introduzione e cura di Valentino Gerratana. Roma, Editore Riuniti.

VACCA, Giuseppe. (2012), Vida e pensamento de Antonio Gramsci (1926-1937). Rio de Janeiro/Brasília, Contraponto/Fundaçáo Astrojildo Pereira.

VIVO, Giancarlo de. (2017), Nella bufera del Novecento: Antonio Gramsci e Piero Sraffa tra lotta politica e teoria critica. Roma, Castelvecchi. 


\section{GRAMSCI, CROCE E A HISTÓRIA POLÍTICA DOS INTELECTUAIS}

\section{Alvaro Bianchi}

Palavras-chave: Intelectuais; História dos Intelectuais; Antonio Gramsci; Benedetto Croce.

Um dos projetos desenvolvidos por Antonio Gramsci consiste em uma ampla crítica das ideias do filósofo Benedetto Croce. Inicialmente concebida como parte de uma pesquisa sobre a teoria da história e da historiografia, essa crítica desloca-se, gradativamente, em direção a uma história política dos intelectuais italianos da qual Croce seria um dos protagonistas. Este artigo reconstrói o percurso dessa pesquisa no interior dos Quaderni del carcere, cotejando-os com a correspondência que seu autor manteve com Tatiana Schucht e, por intermédio dela, com Piero Sraffa. Essa reconstrução permite jogar novas luzes sobre o próprio método de investigação de Antonio Gramsci, o qual assume como princípio a identidade entre filosofia, história e política.

\section{GRAMSCI, CROCE AND THE POLITICAL HISTORY OF THE INTELLECTUALS}

\section{Alvaro Bianchi}

Keywords: Intellectuals; History of Intellectuals; Antonio Gramsci; Benedetto Croce.

One of the projects developed by Antonio Gramsci consists of a broad criticism of the ideas of the philosopher Benedetto Croce. Initially conceived as part of a research on the theory of history and of historiography, this critique gradually moves towards a political history of Italian intellectuals of which Croce would be one of the protagonists. This article reconstructs the course of this research inside the Quaderni del carcere, comparing them with the correspondence that its author maintained with Tatiana Schucht and, through her, with Piero Sraffa. This reconstruction allows us to shed light on Antonio Gramsci's own method of investigation, which assumes as a principle the identity between philosophy, history and politics.

\section{GRAMSCI, CROCE ET L'HISTOIRE POLITIQUE DES} INTELLECTUELS

\section{Alvaro Bianchi}

Mots-clés: Intellectuels; Histoire des intellectuels; Antonio Gramsci; Benedetto Croce.

L'un des projets développés par Antonio Gramsci consiste en une importante critique des idées du philosophe Benedetto Croce. Conçue initialement dans le cadre d'une recherche sur la théorie de l'histoire et de l'historiographie, cette critique se déplace graduellement vers une histoire politique des intellectuels italiens de laquelle Croce serait l'un des protagonistes. Cet article reconstruit le parcours de cette recherche au sein des Quaderni del carcere (Carnets de prison), tout en les confrontant avec la correspondance que son auteur entretenait avec Tatiana Schucht et, par son intermédiaire, avec Piero Sraffa. Cette reconstruction permet de lancer une nouvelle lumière sur la méthode de recherche d'Antonio Gramsci qui assume, en tant que principe, l'identité entre la philosophie, l'histoire et la politique. 